$$
\begin{gathered}
\text { 이중 주파수 및 다중 위성항법 광역보강시스템 한반도 지역 } \\
\text { 성능 예측 }
\end{gathered}
$$

\title{
Performance Estimation of Dual Frequency and Multi-Constellation Satellite Based Augmenation System for Korean Region
}

\author{
윤호*, 한덕화*, 기창돈 ${ }^{* 0}$ \\ Ho Yun*, Deok-Hwa Han ${ }^{*}$ and Chang-Don Kee ${ }^{* 0}$ \\ 요 약
}

최근에 GPS의 현대화, GLONASS의 정상화, Galileo 및 Beidou의 개발 등으로 기존에 GPS에만 의존하였던 것 과 달리 사용자가 다양한 항법위성을 활용할 수 있게 되었다. 또한 새로운 항법위성에는 기존의 L1 주파수 신 호 뿐만 아니라 새로운 민간 신호인 L5 주파수 신호도 방송하기 때문에 사용자는 이중 주파수 측정치를 활용 하여 직접 자신의 전리층 지연을 추정하여 가용성 성능을 향상 시킬 수 있을 것으로 예상된다. 이에 따라 기존 의 GPS L1 주파수 사용자만 고려하던 광역보강시스템도 이중 주파수 및 다중 위성항법시스템을 고려하도록 개 발이 진행되고 있다. 본 논문에서는 미래의 L1/L5 이중 주파수 및 다중 위성항법 시스템 사용자를 고려한 위성 기반 광역보강시스템 (Satellite Based Augmentation System, SBAS)의 주요 알고리즘을 설명하고, 한반도 주변의 성능을 시뮬레이션을 통해 예측하였다.

\section{Abstract}

Recently, GNSS users can utilize various navigation satellite thanks to GPS modernization, renewal of GLONASS, and development of Galileo and Beidou. And availability performance of users is expected to be improved because these new navigation satellites transmit L5 signal as well as L1 signal, and users can directly estimate the ionospheric delays. In accordance with these changes existing Satellite Based Augmentation System (SBAS) which considers only GPS L1 signal is being developed to support dual frequency and multi-constellation GNSS users. This paper describes the main features of dual-frequency, multi-constellation SBAS algorithms and estimates the performance in Korean region by simulation.

Key words : Dual frequency GNSS, Multi-constellation GNSS, SBAS

$$
\text { I. 서 론 }
$$

GPS 현대화가 진행됨에 따라 가까운 미래에 모든
GPS위성에서 L1과 L5 주파수의 민간 신호를 방송할 것으로 예상된다. 뿐만 아니라 러시아의 GLONASS, 유럽의 Galileo 및 중국의 Beidou도 이중주파수 민간

* 서울대학교 기계항공공학부, 항공우주신기술연구소(School of Mechanical and Aerospace Engineering, Institute of Advanced Aerospace Technology

· 제1저자 (First Author) : 윤호(Ho Yun)

0 교신저자 (Corresponding Author) : 기창돈(Changdon Kee, tel : +82-2-880-1912, kee@snu.ac.kr)

· 접수일자 : 2013년 6월 17일 · 심사(수정)일자 : 2013년 6월 19일 (수정일자 : 2013년 8월 21일) · 게재일자 : 2013년 8월 30일 http://dx.doi.org/10.12673/jkoni.2013.17.4.396 
신호를 방송하는 위성항법시스템을 구축하고 있다. 이러한 상황에서 기존의 GPS L1 신호에 대한 보강정 보만을 제공하던 SBAS도 이중 주파수 및 다중 위성 항법시스템 사용자에게 서비스를 제공할 수 있도록 개발이 진행되고 있고, 이에 대한 국제 표준이 2014 년 경에 발표될 예정이다.

기존의 SBAS는 단일 주파수 사용자를 고려하였기 때문에 서비스 영역의 격자 수직 전리층 지연값 및 이에 대한 신뢰수준을 추정하여 사용자에게 제공한 다 [1]. SBAS 사용자는 광역보강정보에 포함되어 있 는 격자 수직 전리층 지연값을 자신의 측정치의 전리 층 통과점 위치에 맞도록 선형 보간하여 전리층 지연 을 제거한다. 사용자는 자신의 측정치 전리층 통과점 부근의 값을 사용하여 간접적으로 전리층 지연을 추 정하기 때문에 이에 대한 신뢰도가 떨어질 수 밖에 없게 되고, 결과적으로 측정치 신뢰도 부족으로 인해 사용자의 가용성 성능이 일정 수준 이상으로 향상되 기 어렵게 된다. 실제로 현재 운용되고 있는 미국의 WAAS (Wide Area Augmentation System), 유럽의 EGNOS (European Geostationary Navigation Overlay Service), 일본의 MSAS (Multi-functional Satellite Augmentation System) 등은 LPV 또는 LPV-200까지의 가용성 성능을 보이고 있으며, 이 한계에 대한 가장 큰 원인이 격자 전리층 보정정보의 불확실성으로 인 해 사용자의 보호수준의 증가이다.

하지만 앞서 설명하였듯이 새로운 항법 위성이 추 감됨으로써 사용자는 사용 가능한 측정치의 개수가 증가하게 되어 전체적인 시스템의 신뢰도가 향상될 것으로 기대되고, 각각의 항법위성에서 이중 주파수 측정치를 활용할 수 있게 됨에 따라 사용자가 직접 자신의 측정치의 전리층 지연값을 추정할 수 있게 되 어 이에 대한 신뢰도가 대폭 향상될 수 있을 것으로 기대된다. 이를 위해 이중주파수 측정치를 활용하였 을 때의 광역보강시스템 알고리즘 구현에 대한 연구 가 진행되었다 [3], [4], [5]. 본 논문에서는 이러한 이 중주파수 및 다중 위성항법 시스템을 고려한 SBAS 의 주요 알고리즘에 대해 설명하고 이에 대한 성능을 시뮬레이션을 통해 분석하도록 한다.
II. 이중주파수 다중 위성항법 광역보강

$$
\text { 시스템 알고리즘 }
$$

이중 주파수 다중 위성항법 광역보강 시스템의 구 현을 위해서는 크게 두 가지 요소를 고려하여야 한 다. 첫 번째는 각각의 위성항법시스템의 시각 및 좌 표계의 동기이다. GPS, Galileo, GLONASS 등 각각의 위성항법시스템은 서로 다른 기준 시각 및 좌표계를 사용한다. 따라서 각각의 시스템을 모두 이용하여 항 법해를 계산하는 경우 서로 다른 시간 및 좌표에 대 한 고려가 필요하다. 두 번째로 고려하여야 할 요소 는 이중주파수를 사용한 전리층 지연 추정에 대한 사 항이다. 기존의 광역보강시스템은 전리층 지연값과 이에 대한 신뢰수준을 보강 메시지에 실어서 방송하 기 때문에 사용자는 이에 대한 처리만 하면 되었지 만, 이중주파수 측정치를 활용할 경우 이 전리층 지 연값과 이에 대한 신뢰수준을 사용자의 측정치를 활 용하여 직접 추정하게 된다. 본 장에서는 $\mathrm{GPS}$, Galileo 및 GLONASS를 사용하였을 때 이 두 가지 고 려 사항에 대한 해결 방법을 설명하도록 한다.

\section{2-1 다중위성항법시스템 기준 시각 및 좌표계} 동기

$\mathrm{GPS}$ 와 Galileo의 경우 각각의 기준 좌표계의 차이에 의한 오차는 $\mathrm{cm}$ 수준 이하이므로 무시할 수 있을 정도 이다. 따라서 GPS와 Galileo와의 통합에서는 서로 다른 기준 시간에 의한 오차만을 고려하면 된다.

$\mathrm{GPS}$ 의 경우 GPS time을 기준 시각으로 사용하고, Galileo system time을 기준 시각으로 사용한다. GPS time과 Galileo system time의 차이를 GGTO (GPS and Galileo Time Offset)라 하며, 그 크기는 약 십 여 나노초 이다. 각각의 위성항법시스템의 기준시각 차이를 고려 하여 항법해를 구하는 방법은 크게 두 가지 방법으로 나눌 수 있다. 첫 번째 방법은 항법 메시지에 포함되어 있는 GGTO 값을 이용하는 방식이다. 먼저 수신기 시계 오차를 제외한 기타 오차 항들을 제외하고 GPS, Galileo 각각의 의사거리 측정치를 나타내면 다음과 같다.

$$
\rho_{G P S}^{i}=\left(\bar{R}_{G P S}^{i}-\overline{R_{u}}\right) \cdot \hat{e}_{u}^{i}+B_{G P S}
$$




$$
\rho_{G A L}^{i}=\left(\bar{R}_{G A L}^{i}-\overline{R_{u}}\right) \cdot \hat{e}_{u}^{i}+B_{G A L}
$$

여기서 $\rho_{G P S}^{i}$ 는 GPS 의사거리, $\rho_{G A L}^{i}$ 는 Galileo 의 사거리, $\bar{R}_{G P S}$ 는 $\mathrm{GPS}$ 위성의 위치벡터, $\bar{R}_{G A L}$ 는 Galileo 위성의 위치벡터, $B_{G P S}$ 와 $B_{G A L}$ 는 각각 $\mathrm{GPS}$ 및 Galileo의 수신기 시계오차를 의미한다. 여기에서 $\mathrm{GGTO}$ 는 다음과 같이 GPS, Galileo 기준시각에 대한 수신기 시계오차의 차이로 나타낼 수 있다.

$$
\Delta G G T O=B_{G P S}-B_{G A L}
$$

이를 아래의 식과 같이 기존의 항법 방정식에 추 가하여 통합 항법해를 구할 수 있게 된다.

$$
\begin{aligned}
& \bar{R}_{u} \cdot \hat{e}_{u}^{i}-B_{G P S}=-\rho_{G P S}^{i}+\bar{R}_{G P S}^{i} \cdot \hat{e}_{u}^{i} \\
& \bar{R}_{u} \cdot \hat{e}_{u}^{j}-B_{G A L}=-\rho_{G A L}^{i}+\bar{R}_{G A L}^{i} \cdot \hat{e}_{u}^{j}
\end{aligned}
$$

$$
\left[\begin{array}{ccc}
\hat{e}_{u, G P S}^{1} & 1 & 0 \\
\vdots & \vdots & \vdots \\
\hat{e}_{u, G P S}^{n} & 1 & 0 \\
\hat{e}_{u, G A L}^{j} & 0 & 1 \\
\vdots & \vdots & \vdots \\
\hat{e}_{u, G A L}^{m} & 0 & 1 \\
\overline{0} & 1 & -1
\end{array}\right]\left(\begin{array}{c}
x \\
y \\
z \\
-B_{G P S} \\
-B_{G A L}
\end{array}\right]=\left[\begin{array}{c}
-\rho_{G P S}^{1}-\bar{R}_{G P S}^{1} \cdot \hat{e}_{u, G P S}^{1} \\
\vdots \\
-\rho_{G P S}^{n}-\bar{R}_{G P S}^{i} \cdot \hat{e}_{u, G P S}^{n} \\
-\rho_{G A L}^{1}-\bar{R}_{G A L}^{1} \cdot \hat{e}_{u, G A L}^{1} \\
\vdots \\
-\rho_{G A L}^{m}-\bar{R}_{G A L}^{m} \cdot \hat{e}_{u, G A L}^{m} \\
\Delta G G T O_{b r a a d c a s t}
\end{array}\right]
$$

두 번째 방식은 항법메시지의 GGTO 값을 이용하 지 않고 $\mathrm{GGTO}$ 를 미지수로 둔 채 항법 방정식을 구 성하는 방식이다. 이 경우 Galileo의 수신기 시계오차 값은 GPS 수신기 시계오차와 GGTO로 나타내게 되 고 이를 식으로 표현하면 다음과 같다.

$$
\begin{gathered}
\bar{R}_{u} \cdot \hat{e}_{u}^{i}-B_{G P S}=-\rho_{G P S}^{i}+\bar{R}_{G P S}^{i} \cdot \hat{e}_{u}^{i} \\
\bar{R}_{u} \cdot \hat{e}_{u}^{j}-B_{G A L}=\bar{R}_{u} \cdot \hat{e}_{u}^{j}-\left(B_{G P S}-\Delta G G T O\right) \\
=-\rho_{G A L}^{j}+\bar{R}_{G A L}^{j} \cdot \hat{e}_{u}^{j} \\
{\left[\begin{array}{ccc}
\hat{e}_{u, G P S}^{1} & 1 & 0 \\
\vdots & \vdots & \vdots \\
\hat{e}_{u, G P S}^{n} & 1 & 0 \\
\hat{e}_{u, G A L}^{1} & 1 & 1 \\
\vdots & \vdots & \vdots \\
\hat{e}_{u, G A L}^{m} & 1 & 1
\end{array}\right]\left(\begin{array}{c}
x \\
y \\
z \\
-B_{G P S} \\
\Delta G G T O
\end{array}\right)=\left[\begin{array}{c}
-\rho_{G P S}^{1}+\bar{R}_{G P S}^{1} \cdot \hat{e}_{u, G P S}^{1} \\
\vdots \\
-\rho_{G P S}^{n}+\bar{R}_{G P S}^{n} \cdot \hat{e}_{u, G P S}^{n} \\
-\rho_{G A L}^{1}+\bar{R}_{G A L}^{1} \cdot \hat{e}_{u, G A L}^{1} \\
\vdots \\
-\rho_{G A L}^{m}+\bar{R}_{G A L}^{m} \cdot \hat{e}_{u, G A L}^{m}
\end{array}\right]}
\end{gathered}
$$

GLONASS 기준 시각은 러시아 모스크바 부근의 UTC를 기준으로 표시되며, GPS time과는 윤초(leap second)만큼의 차이를 가지고 있다. 따라서 앞서 설명 한 GGTO와 비슷한 방식으로 기준 시각 차이에 대한 고려를 해주어야 하며, GLONASS 기준 시각을 GPS 기준 시각으로 변화시키는 식은 아래와 같다.

$$
\begin{gathered}
t_{G P S}=t_{G L O N A S S}+\tau_{c}+\tau_{u}+\tau_{g}+\tau_{r} \\
\tau_{c}=t_{U T C(S U)}-t_{G L O N A S S} \\
\tau_{u}=t_{U T C}-t_{U T C(S U)} \\
\tau_{g}=t_{G P S}-t_{U T C}
\end{gathered}
$$

$$
\tau_{r}=G L O N A S S \text { 와 } G P S \text { 간의 수신기 시계 편이 }
$$

GLONASS에서 사용하는 좌표계는 PZ-90으로 중 심이 지구 질량 중심에 위치하는 좌표계이다. 그리고 $\mathrm{Z}$ 축은 IERS에 의해 재정의된 CTP (Conventional Terrestrial Pole)의 방향이고, X축은 그리니치 자오선 과 지구 적도면의 교차점 방향이며, $\mathrm{Y}$ 축은 오른손 좌표계로 완성된다. GLONASS와 GPS의 좌표계는 이 미 발표된 변환 공식을 이용하여 GLONASS의 좌표 계를 GPS의 좌표계인 WGS-84로 변화하여 사용한다. PZ-90 좌표계를 WGS-84 좌표계로 변환하는 식은 다 음과 같다.

$$
\begin{aligned}
& \left(\begin{array}{c}
X \\
Y \\
Z
\end{array}\right) W G S 84=\left(\begin{array}{l}
-0.47 m \\
-0.51 m \\
-1.56 m
\end{array}\right) \\
& +\left(1+22 \times 10^{-9}\right) \text {. } \\
& \left(\begin{array}{ccc}
1 & -1.728 \times 10^{-6}-0.017 \times 10^{-6} \\
1.728 \times 10^{-6} & 1 & 0.076 \times 10^{-6} \\
0.017 \times 10^{-6}-0.076 \times 10^{-6} & 1
\end{array}\right)\left(\begin{array}{c}
U \\
V \\
W
\end{array}\right) P Z 90
\end{aligned}
$$

다중위성항법 광역보강시스템에서는 이상에서 설 명한 방식들을 활용하여 각각의 위성항법 시스템 간 에 존재하는 시각 및 위치의 바이어스를 제거하고 기 존의 광역보강시스템 알고리즘을 적용하여 위성궤도 오차 및 사용자 위치해를 추정하게 된다.

2-2 이중주파수 측정치를 활용한 사용자 전리 층 지연 추정

앞서 설명하였듯이 기존의 광역보강시스템은 L1 주파수 신호 사용자만을 고려한 서비스를 제공하기 
때문에, 상대적으로 불확실성이 큰 전리층 지연에 대 한 영향이 사용자 가용성에 가장 큰 영향을 미친다. 하지만 이중주파수를 활용할 경우 사용자가 외부의 도움 없이 자신의 측정치의 전리층 지연을 효과적으 로 추정할 수 있게 된다. 따라서 외부 시스템에 의존 하여 사용자의 전리층 지연을 추정하는 단일 주파수 광역보강시스템 사용자에 비해 전리층 지연 추정의 불확실성이 크게 줄어들게 되어 사용자의 보호수준 이 줄어들게 되고 결과적으로 가용성이 증대되는 효 과를 얻을 수 있다. L1, L5 이중주파수 측정치를 활 용하여 전리층 지연값을 추정하는 방법은 [2]에 자세 히 나와 있다. [2]에 나타난 방법대로 사용자 측정치 의 전리층 지연을 추정하였을 경우 이에 대한 신뢰수 준은 아래의 식과 같이 나타낼 수 있다.

$$
\sigma_{j, D F_{-} a i r}^{2}=\left(\frac{f_{1}^{2}}{f_{1}^{2}-f_{5}^{2}}\right)^{2} \sigma_{L 1, j, a i r}^{2}+\left(\frac{f_{5}^{2}}{f_{1}^{2}-f_{5}^{2}}\right)^{2} \sigma_{L S, j, a i r}^{2}
$$

표 1. L1/L5 오차 수준

\begin{tabular}{|c|c|c|c|c|}
\hline & $\begin{array}{l}\text { L1 } \\
\text { only }\end{array}$ & $\begin{array}{c}\text { lono-fre } \\
\mathrm{e} \\
\text { (L1/L5) }\end{array}$ & $\begin{array}{l}\text { Nominal } \\
\text { error }\end{array}$ & $\begin{array}{l}\text { Max } \\
\text { error }\end{array}$ \\
\hline $\begin{array}{c}\text { 전리증 } \\
\text { 위성 궤도 } \\
\text { 및 시계 }\end{array}$ & $\begin{array}{l}1 \\
1\end{array}$ & $\begin{array}{l}0 \\
1\end{array}$ & $\begin{array}{c}0.2-1 \mathrm{~m} \\
0.03-0.5 \mathrm{~m}\end{array}$ & $\begin{array}{c}50 \mathrm{~m} \\
\infty\end{array}$ \\
\hline 대류층 & 1 & 1 & $0.05-0.5 \mathrm{~m}$ & $5 \mathrm{~m}$ \\
\hline $\begin{array}{l}\mathrm{L} 1 \text { 측정치 } \\
\text { 잡음 }\end{array}$ & 1 & $\begin{array}{l}\frac{f_{1}^{2}}{f_{1}^{2}-f_{5}^{2}} \\
=2.26\end{array}$ & $0.15-0.5 \mathrm{~m}$ & $0.5 \mathrm{~m}$ \\
\hline $\begin{array}{c}\mathrm{L} 5 \text { 측정치 } \\
\text { 잡음 }\end{array}$ & 0 & $\begin{array}{c}f_{5}^{2} \\
f_{1}^{2}-f_{5}^{2} \\
=1.26\end{array}$ & $\begin{array}{c}0.15-0.5 \\
\mathrm{~m}\end{array}$ & $0.5 \mathrm{~m}$ \\
\hline RSS & 1 & 2.6 & $0.4-1.3 \mathrm{~m}$ & $1.3 \mathrm{~m}$ \\
\hline
\end{tabular}

표 1 은 $\mathrm{L} 1$ 주파수 측정치의 오차를 1 로 두었을 때 $\mathrm{L1}, \mathrm{L} 5$ 주파수 측정치를 조합하여 사용하였을 때 각 각의 오차요소에 대한 비율을 나타낸 표이다 [4]. Nominal error는 정상 상태에서의 오차 수준으로 사 용자의 정확도 성능에 영향을 미치고, max error는 이 상 상태에서의 오차 수준으로 사용자의 무결성 및 가 용성 성능에 미친다고 볼 수 있다. 위의 표에서 알 수 있듯이 L1 주파수만 사용 시, GNSS의 주요 오차 요 인 중에서 전리층 지연에 의한 오차가 가장 큰 비중 을 차지하며, 특히 최대 오차 값이 약 $50 \mathrm{~m}$ 수준으로
이러한 오차 발생 시 사용자의 정확성 및 가용성이 크게 저하되게 된다. 반면 L5 주파수 신호도 함께 사 용할 경우 측정치 조합으로 전리층 지연을 제거할 수 있으므로 전리층 이상 발생 시에도 비교적 높은 수준 의 정확성 및 가용성을 유지할 수 있다. 하지만 이 경 우 두 개의 측정치를 조합하여 사용하기 때문에 측정 치의 잡음 수준이 높아지게 되고 이에 따라 전체적인 정상상태의 오차 수준은 높아지게 되어 정상 상태에 서의 사용자 정확성은 약간 저하될 수 있다 [6].

III. 이중주파수 다중위성항법 광역보강시스템 성능 예측 시뮬레이션

\section{3-1 시뮬레이션 설정}

앞서 설명한 이중 주파수 다중 위성항법 광역보강 시스템의 성능을 확인하기 위하여 한반도 주변지역 에 대한 시뮬레이션을 통해 정확성, 가용성 등의 성 능을 확인해 보기로 한다. 먼저 이중 주파수 측정치 사용에 대한 이점을 보기 위하여 GPS L1 주파수 신 호만 사용하는 기존의 광역보강시스템 사용자 성능 과 GPS 이중 주파수 광역보강시스템의 성능을 확인 하도록 한다. 그 다음으로는 다중 위성항법시스템 사 용의 이점을 확인하기 위하여 GPS만 사용하였을 때 와 GPS, GLONASS, Galileo를 함께 사용하였을 때의 성능을 비교해 보도록 한다. 시뮬레이션 시간은 24시 간이고 각각의 오차요소의 생성방법은 표 2에 표시 하였다. 광역보강시스템 기준국은 내륙의 외곽에 위 치한 4 개의 공항(김포, 양양, 목포, 김해)에 위치하여 있다고 가정하고 시뮬레이션을 진행하였고, 사용자 는 한반도 부근에 위도, 경도 5 도 간격으로 배치하여 사용자의 위치에 따른 항법 성능을 분석하였다.

표 2. 오차 요인 및 생성 방법

Table 2. Error Sources and Generation Method

\begin{tabular}{l|l}
\hline 오차 요인 & 오차 생성 방법 \\
\hline 수신기 시계 오차 & $2^{\text {nd }}$ order Markov Process \\
\hline 전리층 지연 오차 & IONEX \\
\hline 대류층 지연 오차 & Black Model \\
\hline 대류층 지연 잡음 & $1^{\text {st }}$ order Markov Process \\
\hline 수산지집음및멸티패스오차 & Function of Elevation Angle \\
\hline
\end{tabular}


3-2 시뮬레이션 결과
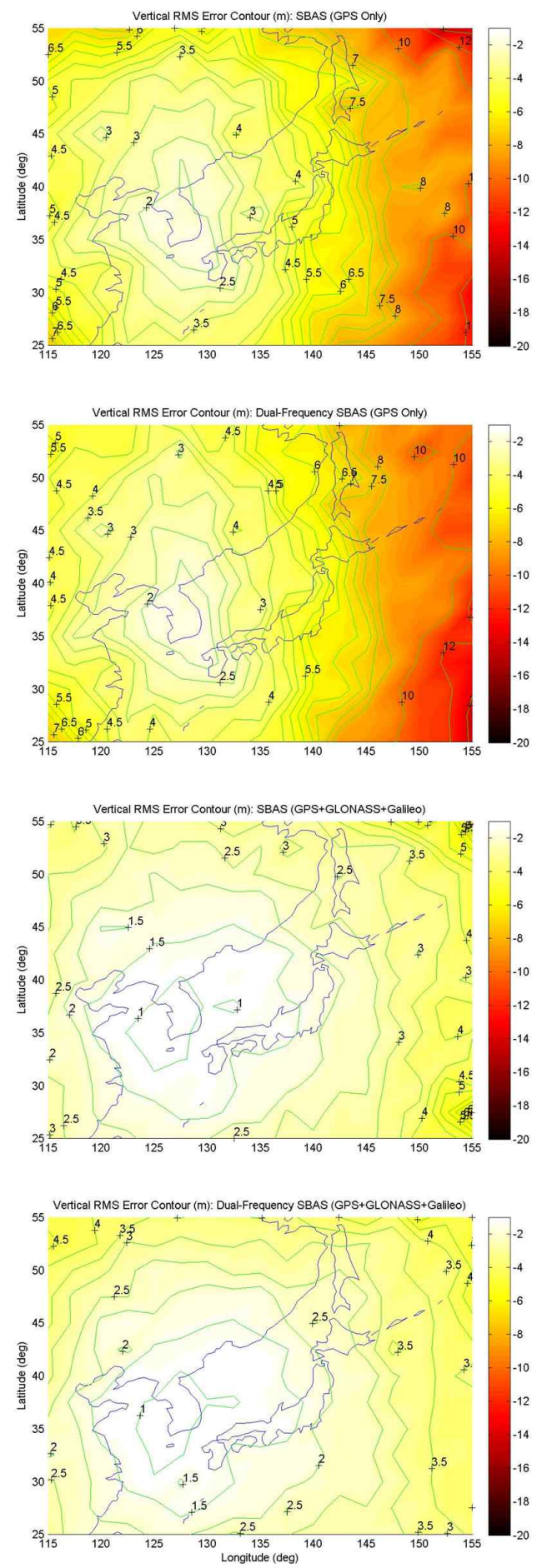

그림 1. 광역보강시스템 사용자 수직 위치오차 Fig. 1. Vertical Position Errors of SBAS User
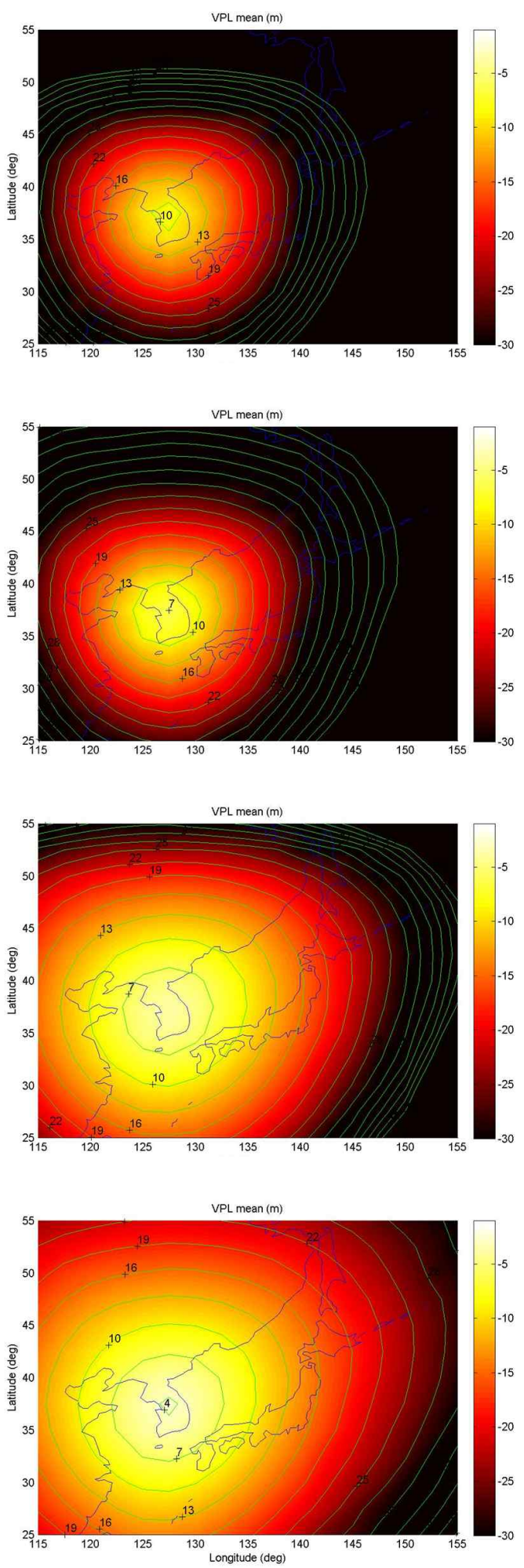

그림 2. 광역보강시스템 사용자 수직 보호수준 Fig. 2.Vertical Protection Levels of SBAS User 

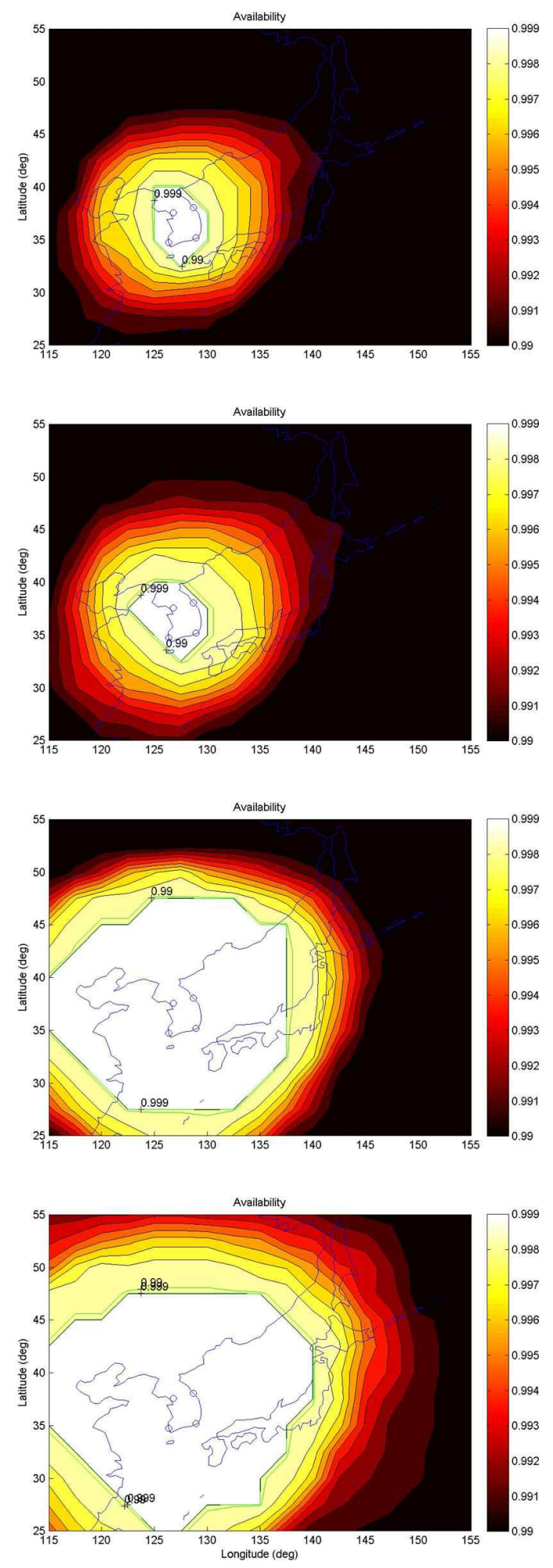

그림 3. 광역보강시스템 사용자 가용성 성능

Fig. 3. LPV Availability Performance of SBAS User.
그림 $1 \sim 3$ 은 각각 본 연구에서 구현한 4가지 광역 보강시스템의 수직 위치오차, 수직 보호수준, LPV 가 용성을 나타낸 그림으로, 위에서부터 차례대로 GPS $\mathrm{L} 1$ 단일 주파수 광역보강시스템, GPS L1/L5 이중주 파수 광역보강시스템, $\mathrm{GPS} / \mathrm{GLONASS} / \mathrm{Galileo}$ 단일 주파수 광역보강시스템, GPS/GLONASS/Galileo 이중 주파수 광역보강시스템에 대한 성능이다. 그림 1 의 첫 번째와 두 번째 그림을 살펴보면 SBAS 사용자가 이중주파수 측정치를 활용하여도 단일주파수 측정치 만 사용하였을 때와 정확도 성능의 차이가 거의 없고 오히려 약간 성능이 저하되는 것을 볼 수 있다. 이는 앞서 설명하였듯이 사용자가 이중주파수 측정치를 조합하여 전리층을 제거하기 때문에 정상상태의 측 정치의 잡음 수준이 2.6 배 정도 증가하기 때문이다. 하지만 전리층 오차 추정에 대한 신뢰수준이 증가하 기 때문에 사용자의 보호수준은 더욱 정밀하게 추정 할 수 있게 되고 이로 인하여 그림 2에서 볼 수 있듯 이 보호수준이 작아지는 것을 알 수 있다. 그림 2에 서 GPS L1 광역보강시스템 사용자는 서비스 중심영 역 일부에서만 평균 $10 \mathrm{~m}$ 정도의 수직 보호수준 값 을 갖는 것에 비해 GPS L1/L5 이중주파수 광역보강 시스템 사용자는 한반도 전역에 걸쳐 평균 $10 \mathrm{~m}$ 이 하의 수직보호 수준을 갖는 것을 확인할 수 있다. 이 로 인한 LPV 가용성 증가도 그림 3의 첫 번째와 두 번째 그림에서 확인할 수 있다. 그림 $1 \sim 3$ 의 세 번째 와 네 번째 그림들을 보면, GPS에 GLONASS와 Galileo가 추가되면 단일 주파수 및 이중 주파수 광역 보강시스템 모두의 정확도 및 가용성 성능이 눈에 띄 게 증가하게 되는 것을 볼 수 있다. 이는 사용 가능한 측정치의 개수가 약 3 배로 증가하기 때문에 항법위 성의 기하학적 배치가 좋아지고 사용자 항법해의 신 뢰수준이 증가하기 때문이다. 특히 이중주파수 광역 보강시스템을 구축하였을 경우 한반도 주변은 물론 일본 및 중국 일부 지역까지 LPV 서비스가 가능할 정도로 성능이 좋아질 것으로 예상된다.

\section{$\mathrm{V}$. 결 론}

본 논문은 위성항법시스템의 수 및 사용 주파수의 
수에 따른 광역보강시스템의 한반도 인근의 성능을 시뮬레이션을 통해 예측하였다. 시뮬레이션을 위해 기존의 광역보강시스템 알고리즘에 서로 다른 위성 항법시스템 간의 좌표계 및 기준 시각 동기화 알고리 즘을 구현하여 적용하였고, 이중 주파수 측정치를 활 용한 사용자 전리층 지연 및 그 신뢰 수준을 추정하 였다. 시뮬레이션 결과 항법 시스템의 추가 없이 사 용 주파수가 추가되었을 때에는 정확도 성능에는 큰 차이가 없지만 가용성 성능이 증가하는 것을 확인하 였고, 항법 시스템이 추가될 경우 정확도 및 가용성 성능이 모두 향상될 것으로 예측된다. 시뮬레이션 결 과 가용성 성능 향상 정도는 사용 주파수가 추가될 때보다 항법 위성이 추가될 때 더 크게 나타났는데, 그 이유는 우리나라의 광역보강시스템 서비스 영역 이 비교적 좁기 때문에 기준국이 다른 나라의 광역보 강시스템 기준국들에 비해 밀집하여 분포해 있고, 따 라서 전리층 지연의 추정 신뢰수준이 충분히 높기 때 문으로 풀이된다. 다수의 항법시스템을 활용한 광역 보강시스템을 구축할 경우 위성의 기하학적 배치 조 건이 좋아지고 가시 위성 수가 증가하여 사용자의 정 확도는 물론 가용성, 서비스 영역 등이 크게 증가하 게 되어 위성항법시스템의 활용범위가 늘어날 것으 로 예상된다. 본 연구에서 수행된 한반도 지역의 다 중 위성항법 보강시스템의 성능 예측 분석 결과는 향 수 다중 위성항법 보강시스템 구축시 참고자료로 활 용될 수 있고, 또한 본 연구에서 개발된 시뮬레이션 툴을 활용하여 최적의 기준국 배치, 서비스 성능 예 측 등에 활용할 수 있을 것으로 기대된다.

\section{감사의 글}

본 논문은 서울대학교 정밀기계설계 공동연구소 를 통해 계약된 해양수산부의 "광역보정시스템 (WA-DGNSS) 구축기술개발" 과제의 지원에 의함.

\section{Reference}

[1] RTCA SC-159, Minimum Operational Performance Standards for Global Positioning System/Wide Area
Augmentation System Airborne Equipment, RTCA publication DO-229D, 2006

[2] G. A. McGraw, Y. Young, "Dual Frequency Smoothing DGPS Performance Evaluation Studies", Proceedings of the National Technical Meeting of the ION, San Diego, CA, 2005.

[3] T. Walter, J. Blanch, P. Enge, "Vertical Protection Level Equation or Dual Frequency SBAS“, Proceedings of 23rd International Technical Meeting of the ION, pp. 2031-2041, 2010.

[4] T. Walter, J. Blanch, R. E. Phelts, P. Enge, "Evolving WAAS to Serve L1/L5 Users", Journal of Institute of Navigation, Vol. 56, No. 4, pp. 317-327, 2012.

[5] GEAS, "GNSS Evolutionary Architecture Study Phase II Panel Report", avaiable at http://www.faa.gov/about/office_org/headquarters_of fices/ato/service_units/techops/navservices/gnss/libra ry/documents/media/GEASPhaseII_Final.pdf

[6] T. Walter, J. Blanch, P. Enge, "Evaluation of Signal in Space Error Bounds to Support Aviation Integrity", Proceedings of 22nd International Technical Meeting of the IOM, pp. 1317 - 1329, 2009

\section{윤 호 (Ho Yun)}

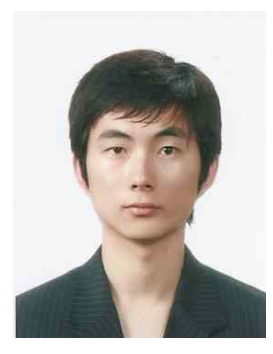

2006년 2월 : 서울대학교 기계항공 공학부(공학사) 2013년 2월 : 서울대학교 기계항공 공학부(공학박사) 2013년 3월 현재 : 서울대학교 기계 항공공학부 선임연구원 관심분야 : 무결성 감시, 광역보강시스템

\section{한 덕 화 (Deok-Hwa Han)}

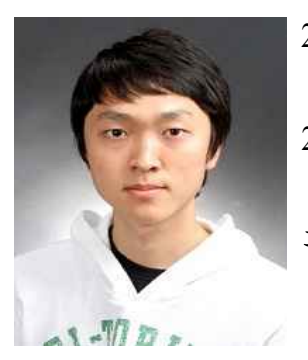

2011년 2월 : 서울대학교 기계항공 공학부(공학사)

2011년 3월 현재 : 서울대학교 기계항공공학부 석박통합과정 관심분야 : 광역 보정 항법, 전리층 지연 


\section{기 창 돈 (Chang-Don Kee)}

1984년 2월 : 서울대학교 항공

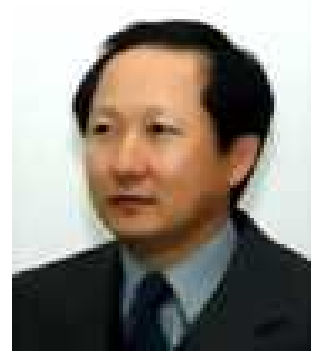

공학과(공학사)

1986년 2월 : 서울대학교 항공

공학과(공학석사)

1994년 1월 : Stanford Univ. 항공

우주공학과(공학박사)

1996년 9월 2000년 9월 : 서울

대학교 기계항공공학부 조교수

2000년 10월 2006년 9월 : 서울대학교 기계항공공학부 부교수

2006년 10월 현재 : 서울대학교 기계항공공학부 교수 관심분야: 위성항법시스템, 실시간 보정위성항법시스템, 실시간 광역보정위성항법시스템, 실시간 초정밀 위치결정 시스템, 항공기/우주비행체 자세결정, 무인항공기 자동 제어 시스템 